\title{
CONSTRUÇÃO DE COMPETÊNCIA: UMA DEMANDA EMERGENTE
}

Marina P. de Arruda:

SÍNTESE - O presente artigo busca tecer algumas considerações sobre o desenvolvimento do Subprojeto de pesquisa Formação instaurando competência que visa verificar como os processos de formação, dado ao contexto sócio-econômico atual, estão-se organizando quanto à construção da competência, demanda recente do mundo do trabalho.
ABSTRACT - This article seeks to make some considerations on the development of the subproject of research entitled Formation creating competence, which aims to verify how the formation processes, given the current socioeconomic context, are organizing themselves concerning the construction of competence, which is a recent demand of the working world.

\section{Construção da competência: uma demanda emergente}

No limiar do século XXI, verifica-se uma mudança no perfil das profissões devido às exigências do mundo atual. Isso porque se impõe à sociedade uma nova forma de organização do trabalho, em que se destacam as empresas capazes de oferecer produtos altamente diferenciados a preços altamente competitivos. Sendo assim, o processo de ajuste dessas empresas alterou profundamente as habilidades exigidas do candidato a emprego.

É nessa perspectiva que o artigo em questão busca tecer algumas considerações sobre como os processos de formação, dado o contexto sócio-econômico atual, estão se organizando quanto à construção de competências, demanda recente do mundo do trabalho.

Essa investigação articula-se à linha de pesquisa "Formação, Trabalho, Instituição e saberes" em andamento há alguns anos e que, desde março de 1995, se vincula ao Projeto Integrado "Urbanidade e Cidadania: processos de formação e instauração de saberes", que desenvolve um conjunto de atividades de caráter interdisciplinar e inter-institucional, envolvendo distintas áreas das Ciências Hu-

Licenciada em Ciências Sociais pela PUCRS e bolsista de aperfeiçoamento da FAPERGS, junto ao Projeto Integrado "Um processo de formação e instauração de saberes", sob a orientação da prof" Julieta B. R. Desaulniers.

\begin{tabular}{|l|l|l|l|l|l|} 
VERITAS & Porto Alegre & v. 42 & $n^{2} 2$ & Junho 1997 & p. 265-271 \\
\hline
\end{tabular}


manas e Sociais. Dentro desse projeto atuo na condição de bolsista junto a FAPERGS e desenvolvo o subprojeto "Formação Instaurando Competência" sob a orientação da prof Julieta B. R. Desaulniers.

Sabemos que o Brasil hoje enfrenta o grande desafio, decorrente do atual contexto econômico-político-şocial, de buscar sua inserção no competitivo mercado mundial. Esse problema ganha cada vez mais dimensão e relevância se considerarmos as divulgações produzidas pela imprensa escrita do país, que tratam dessa questão com grande destaque.

A vida profissional hoje se constitui num aprendizado constante e, com esta preocupação, países e empresas de ponta gastam milhões de dólares na formação e treinamento de seus quadros.

O fato é que se impõe à atual sociedade uma nova forma de organização do trabalho, que requer do trabalhador habilidades como flexibilidade, criatividade, autonomia de decisão, capacidade crítica, etc., pois se buscam a competitividade, a eficiência e a qualidade dos serviços.

Com a abertura da economia, os empresários passam a conviver com novos termos e tendências de mercado. A globalização se instaura e provoca mudanças sem precedentes nas formas de organização do trabalho. Muda o conceito de competitividade, e esta passa a ser mensurada pela capacidade de cada país conviver com os demais numa situação de crescente interdependência mundial.

Baseando-se no entendimento de que as possibilidades de construção da competência em instituição educacional estão diretamente associadas à dinâmica estrutural do campo educativo articulado, ao mesmo tempo, de forma interativa e conflitiva, com a dinâmica estrutural dos demais campos que constituem o espaço social, ${ }^{1}$ num contexto de capital mundializado, disseminação da teoria neoliberal, altos índices de desemprego e exclusão social, acelerađos pelo avanço tecnológico e conseqüenté reorganização do mundo do trabalho, supõe-se que:

- as transformações que vêm ocorrendo no mundo contemporâneo impõem a construção da competência, baseada em habilidades que envolvem todas as dimensões do indivíduo, com ênfase na capacidade crítica e de autonomia, no espírito de iniciativa com audácia, na responsabilidade e na flexibilidade face à mudança e ao inusitado, além de uma visão de empreendedor. Isso implica rupturas tanto na dinâmica interna dos espaços institucionais voltados a esse tipo de formação, como também na própria dinâmica dos demais espaços sociais em que esse individuo atua enquanto cidadão. ${ }^{2}$

A época atual marcada pela exigência de uma reorganização das várias instâncias que compõem a totalidade social instiga-nos e nos desafia a repensar 0 mundo às portas do terceiro milênio.

A complexidade da vida moderna deixa claro que lucramos com o avanço da tecnologia, seja nos produtos industriais, nos serviços que implicam formas de produção ecologicamente mais corretas, na qualidade de vida, etc. Por outro lado,

Esse pressuposto baseia-se no referencial teórico-metodológico de Pierre Bourdieu.

Essa hipótese consta no subprojeto "A formaçāo construindo competência: um desafio à instituição escolar" organizado pela prof Julieta B. R. Desaulniers, e que atualmente desenvolvo como bolsista. 
nos força a conviver com novas tendências, pois o mercado não é mais o mesmo e a competição, o mandamento principal desse processo. Temos então a substituição do conceito de emprego por tarefas a cumprir. As redefinições são profundas, a tal ponto que uma nova palavra se incorpora ao cenário laboral, a empregabilidade, ou seja a capacidade de prestar serviços e obter trabalho. ${ }^{3}$ A virada è radical e ninguém escapa. Um novo perfil de trabalhador é requerido pelo mercado de trabalho e a demanda é pelo sujeito criativo, crítico, capaz de tomar decisões e flexível. Vários são os movimentos de gestão empresarial moderna adotados, e a tendência é de que tenhamos cada vez mais empreendedores e menos empregados.

No Brasil, a mudança nos padrões de emprego ocorreu de forma abrupta. Até 1990, nossa economia era fechada, e os empresários não precisavam se preocupar com a qualidade, pois não havia concorrência. A abertura de nossa economia expõe toda a ineficiência de nossas empresas sem técnicas modernas de gerência e de produção. O próximo passo da reviravolta brasileira foi a modernização das máquinas, pois até 1990 não se podiam importar equipamentos computadorizados. Passados dois anos do início dessa abertura, metade das grandes indústrias já se utilizavam de computadores em larga escala, passando a exigir operários mais bem preparados. O impulso de modernização joga luz sobre um problema ainda mais sério do Brasil, a educação. Metade da população que trabalha tem educação precária, incapaz de operar com eficiência em economias modernas. Como qualificar essas pessoas e reunir esforços contra o desemprego é um dos problemas a ser enfrentado nesse final de século. A educação se torna fator decisivo para o desenvolvimento e a revolução tecnológica que transformaram a economia nas últimas décadas criando um problema para empregadores e trabalhadores. É certo que o Brasil ainda tem um índice relativamente baixo de desempregados comparado a países europeus, isso porque o país cresceu pouco nos anos 80 e tem toda uma infra-estrutura para ser remodelada, o que vai exigir o recrutamento de milhões de trabalhadores. O problema é que, na medida em que nossa economia se moderni$\mathrm{za}$, os bons empregos ficam restritos aos mais bem preparados e muitos estarão excluídos, atuando no mercado informal, outra tendência de nossa época, com baixa remuneração e trabalho precário.

É evidente que o processo de formação sofreu mudanças ao longo dos anos em decorrência das atuais exigências de mercado. Se até à metade desse século a formação tinha um cunho totalizante, rígido e autoritário, hoje a formação se firma em moldes mais globalizantes, ${ }^{4}$ pois vários são os meios de obtenção de saberes. A partir de 1980, podemos verificar que a noção de competência passa a ocupar um lugar de destaque nos sistemas de ensino, redefinindo os modelos pedagógicos, ${ }^{5}$ porque hoje a tecnologia impõe um ritmo acelerado de mudanças sociais e econômicas, implicando uma constante reposição de saberes, não necessariamente

3 Ver jornal Zero Hora, Editoriais, 5/11/96, p. 19.

4 Estas informações podem ser encontradas em: DESAULNIERS, Julieta B. R. Trabalho: a escola do trabalhador? Tese de doutorado defendida junto ao PPGED / UFRGS, maio/93.

5 Ver TANGUY, Lucie. Formação, uma atividade em vias de definição? In Coster \& Pichault (org.) Traité de Sociologie du Travail, Bélgica, Ed. Boeck-W, 1994. 
ligados aos postos de trabalho. Competência, então, pode ser entendida como "a capacidade de resolver um problema numa situação dada. Este conceito e a maneira como o mesmo vem sendo apresentado pela imprensa escrita do país, retratam a importância com que essa demanda tem sido priorizada dentro da nova organização do mundo do trabalho. O assunto é tratado como ordem do dia na maioria dos veículos de comunicação. Nesse sentido, a construção social desse conceito é um estudo importante, pelo movimento que condensa, pelo dinamismo das divulgações cotidianas que delineiam insistentemente o perfil do trabalhador um empreendedor. Como nos mostram alguns trechos de artigos a seguir:

- Em O futuro começa hoje" podemos ler que "a tendência inexorável do homem é o desenvolvimento, é o crescimento, é a evolução", nos convidando a refietir sobre a necessidade de rupturas, pois de acordo com esse autor só aqueles que trilham o caminho da modernidade serão capazes de vencer, apesar dos conservadores.

- O artigo Planejar carreiras é se antecipar às mudanças informa-nos que as previsões são assustadoras para 0 mercado de trabalho da maioria dos brasileiros. A primeira recomendação é a de que se abandonem conceitos antigos, pois a escola do primeiro grau à universidade não é mais o único local onde se formam pessoas, mas apenas mais um lugar onde se buscam informações "essa idéia coloca por terra a visão paternalista do ensino, se a escola vai formar empregados ou empreendedores é o estudante quem vai decidir sobre o seu futuro". Planejar carreiras pressupõe a percepção das exigências do mercado de trabalho, além do que, a melhor maneira de planejar o futuro profissional é ativar todo o círculo de relacionamento em busca de informações, além do domínio do inglês e da informática.

- Em A prioridade número um, encontramos toda uma indicação de um exemplo a ser seguido: "a seriedade com que os americanos encaram a educação... a nação mais rica do mundo[...] alcançou seu extraordinário estágio de desenvolvimento precisamente por conferir precedência à preparação e à capacitação de recursos humanos".

- Outro exemplo está no artigo Diploma vence a experiência ${ }^{10}$ sobre o fato de hoje as empresas estarem dando preferência aos funcionários com curso superior: "Para evoluir dentro de uma empresa é fundamental o diploma, não importando muito a área de formação... quanto maiores os níveis de responsabilidade, maior a exigência de conhecimentos na área , o que torna importantes o curso superior e os cursos de especialização".

- No artigo Ensino e formação: o desafio de novos tempos" podemos ler que "a educação desempenha papel estratégico no projeto neoliberal. Os discursos dos governantes, dos empresários, da mídia enfatizam o tempo

- DESAULNIERS, Julieta B. R.. A formação em busca da competência: uma demanda da atualidade. mímeo.

7 BUZATTO, César. In Zero Hora 7/6/96, p. 21.

8 EDITORIAL. In Zero Hora, 8/9/96, p. 2.

EDITORIAIS. In Zero Hora, 9/2/97, p. 3.

ZH Classificados, 2/3/97, p. 3.

" GARCIA, Regina L. In Revista do CREA, Rio de Janeiro, jan./96, s/p. 
todo a importância da escola de qualidade. Isto porque é indispensável que a educação atenda a todos os objetivos empresariais da preparação adequada para o trabalho com vista à competitividade do mercado internacional [...]"

Estes são alguns exemplos recorrentes do que pudemos ler nos periódicos do país a partir de 1996, a imprensa registrando a tendência de nosso tempo e contribuindo para a construção do conceito social de competência. Conceito este que se amplia, expressando práticas que são assimiladas pela sociedade como um todo. Seja na reorganização da formação através da instauração de provões ao final dos cursos universitários ou na reorganização de currículos escolares e até nos programas emergenciais organizados pelo governo do Estado ("RS Emprego - um trabalho para todos"), com o objetivo de gerar empregos, treinar e qualificar trabalhadores.

A tendência mundial à terceirização faz com que as relações de trabalho assumam outras características. Essas relações não são mais duradouras como antigamente. $\mathrm{O}$ crescente aumento da competitividade, a busca da competência e das aspirações por qualidade, fazem com que surjam o espaço e a necessidade de se preparar um novo trabalhador com as características apontadas por Azambuja, ${ }^{12}$ em recente livro sobre sistemas de qualidade, como sendo imprescindiveis ao novo trabalhador do terceiro milênio. São elas:

- disposição para um aprendizado contínuo,

- capacidade de rompimento com antigos paradigmas,

- pensamento sistêmico e holístico,

- criatividade e inovação,

- capacidade crítica

- disposição para o trabalho em equipe,

- respeito pelo ser humano e pelo ambiente que o cerca,

- habilidade para usar informações, fatos e dados e

- familiarização com a informática.

Esse conjunto de características proposto pelo autor acima citado, sintetiza o perfil do trabalhador competente e é imposto pela nova forma de organização do trabalho. Essa realidade leva os trabalhadores a desenvolverem novas habilidades.

Tendo em vista todos nós que esses acontecimentos registrados, dia após dia pela imprensa, sintetizam e confirmam a necessária reorganização dos diversos processos de formação da sociedade do terceiro milênio é que procuramos realizar um estudo junto às escolas de ofício católicas, buscando verificar a conexão entre o papel dessas escolas e o mundo do trabalho, sabedores que somos da necessidade de inovação dos processos educacionais de nosso pais, que visem possibilitar a construção de competências junto a seus formandos.

${ }^{12}$ AZAMBUJA, Telmo Travassos. Documentos de sistemas de qualidade. Editora Campus Ltda., RJ, 1996, p. 5. 
As colocações acima tornam-se indispensáveis quando se pretende verificar como se tem constituído a formação instaurada nas escolas em questão, a partir de 1990, frente à recente demanda de competência.

Indispensável também se torna a apresentação dos passos metodológicos utilizados ao desenvolvermos esta pesquisa e dos resultados obtidos até então.

\section{Desenvolvimento da pesquisa e alguns resultados}

De março a setembro, as atividades desta pesquisa se desenvolveram apoiadas em fichamento de artigos de jornais, revistas e publicações em geral, tendo em vista as categorias: formação, Estado, emprego/desemprego, globalização e competitividade. A metodologia adotada por este estudo priorizou as publicações da imprensa brasileira durante 0 ano de 1996, na tentativa de se fazer um apanhado geral da tendência do atual mercado de trabalho ao requerer um novo perfil de trabalhador. Essa pesquisa totaliza hoje, aproximadamente cem artigos coletados, devidamente fichados. A imprensa foi utilizada como interface desse trabalho por se tratar de um instrumento ou canal que divulga intenções variadas, consideradas por retratarem a tendência de nosso tempo.

A partir de setembro/96, elaboramos um instrumento para coleta de dados a ser aplicado junto às escolas de ofício católicas: Pão dos Pobres e Centro Social Calábria. Esse documento condensava algumas dimensões consideradas relevantes para essa parte da pesquisa, como por exemplo: flexibilização do espaço, relação teoria e prática, práticas pedagógicas utilizadas, etc., a fim de que pudéssemos verificar em que medida e de que maneira algumas dimensões que configuram a construção da competência, estão sendo instauradas em tais processos de formação.

Vale ressaltar que o levantamento de dados para a pesquisa foi concluído, instrumentos de pesquisa foram utilizados, e estes se constituem em nossos primeiros resultados, porém a análise efetiva de todos os dados será feita com a continuidade da mesma.

A princípio pode-se dizer que já se nota dentro dessas escolas alguma mobilização com o intuito de construir a competência junto a seus alunos, a fim de possibilitar uma maior articulação entre formação e mercado de trabalho, mesmo porque a demanda é emergente e as características demandadas pelo mercado de trabalho, já citadas nesse artigo, são pouco valorizadas até então nos bancos acadêmicos.

\section{Conclusão}

Enfim, com o mundo do trabalho demandando competência, a escola mais do que nunca deverá desenvolver todo um processo no sentido de instaurar a construção da mesma, justificando assim o seu papel, ou seja, fazendo com que a escola responda aos anseios da sociedade e seu cotidiano.

Ao considerarmos o mundo no limiar do século XXI, em que se configura 0 fim da sociedade industrial e o surgimento da sociedade da informática, que inclui um crescente aumento da produtividade e das aspirações por qualidade desenca- 
deadas pela gestão empresarial moderna, verificar a construção de competências é também investigar a predisposição dessas escolas em propor rupturas com o antigo modelo de formação, reforçando assim seu compromisso com as demandas sociais atuais.

De acordo com os primeiros resultados obtidos nessa pesquisa, é possível afirmar que as escolas de ofício católicas investigadas, ao adotarem certas práticas como a flexibilização do espaço, incentivo à capacidade crítica através de leituras de jornais, oportunizarem o trabalho em equipe e propiciarem oficinas de informática, que estimulam o perfil empreendedor, podem estar dando os primeiros passos no caminho da formação de competências para atender a essa emergente demanda. 